\title{
Prediction of Driving Cycles by Means of a Co-Simulation Framework for the evaluation of IC Engine Tailpipe Emissions
}

\author{
Author, co-author (Do NOT enter this information. It will be pulled from participant tab in \\ MyTechZone) \\ Affiliation (Do NOT enter this information. It will be pulled from participant tab in MyTechZone)
}

\begin{abstract}
The reliable prediction of pollutant emissions generated by IC engine powertrains during the WLTP driving cycle is a key aspect to test and optimize different configurations, in order to respect the stringent emission limits. This work describes the application of an integrated modeling tool in a co-simulation environment, coupling a 1D fluid dynamic code for engine simulation with a specific numerical code for aftertreatment modelling by means of a robust numerical approach, to achieve a complete methodology for detailed simulations of driving cycles. The main goal is to allow an accurate 1D simulation of the unsteady flows along the intake and exhaust systems and to apply advanced thermodynamic combustion models for the calculation of cylinder-out emissions. The simulation of the after-treatment systems is then carried out by a steady state model including a detailed chemistry approach, which allows an accurate prediction of the conversion of pollutants under the wide range of operating conditions of a driving cycle. This co-simulation environment has been validated against the measured dataset of an SI, natural gas engine which was instrumented and tested at EMPA labs.
\end{abstract}

\section{Introduction}

The current EU legislation requires to reach a challenging fleet average $\mathrm{CO}_{2}$ emission in 2030 , for both light-duty and heavy-duty vehicles. In addition, pollutant emission limits for IC engine vehicles are very stringent and demanding [1], considering also the expected Euro 7 regulation. A necessary path to reach the targets is clearly represented by a massive electrification/hybridization of vehicle powertrains [2]. Due to the large variety of possible architectures and operating conditions of hybrid thermal-electric vehicles, reliable simulation models are fundamental to quickly investigate and compare different powertrain layouts [3]. Several driving scenarios can be considered, like WLTP cycles and RDE tests, to investigate the performance and emissions of virtual IC engines under realistic operating conditions. With regard to the prediction of pollutant emissions from IC engines, this is a challenge still today. During the last decade, along with the more tightening limits and increased public concern about air quality, the capability of simulating different operating conditions and driving cycles with an acceptable computational effort has become a key feature for modern simulation codes.

Advanced simulation tools can give the opportunity to investigate how to achieve high engine efficiency, low fuel consumption and emissions while keeping good performances, on the basis of the typical operating conditions requested by the WLTP cycle and RDE homologation Page 1 of 13 procedure. Different levels of modeling can be used to meet these objectives and estimate the engine fuel consumption and pollutant emissions in various driving conditions [4]: the kinematic approach, based on a backward methodology and OD black box model of the engine [5], the quasi static approach, in which the power demand profile is determined to follow the target vehicle speed, and the fully dynamic approach, which considers not only the vehicle dynamics equation but also the internal combustion engine behavior during transients modelled by means of detailed 1D fluid-dynamic models.

In particular, 0D-1D thermo-fluid dynamic simulation models can provide a good prediction of the IC engine behavior in terms of air mass flow rate, torque and power, cylinder pressure, unsteady flows, turbocharging condition, fuel consumption and so on, so that the "virtual engine" correctly represents the real one. This engine model can be coupled to accurate models of the after-treatment system and of the vehicle, in order to investigate the performances of the powertrain over a wide range of operating conditions, under steady-state and transient mode [6]. Additionally, in this framework, a suitable integration with the ECU model allows to add the control of several parameters related, for instance, to the cooling systems, the ATS with eventual DEF dosing units, the waste heat recovery unit and also eventual electric power units, allowing to replicate realistic operating conditions of the engine [7-10]

This work describes the application of an integrated modeling tool in a co-simulation environment, coupling a one-dimensional fluid dynamic code for engine simulation, gasdyn (hereafter "1D code") with the numerical code for aftertreatment modelling axisuite (hereafter "ATS code") by means of a robust numerical approach, in order to achieve a complete methodology to perform detailed simulations of driving cycles. Different modelling approaches were considered and compared with an increasing level of complexity but also of computational cost.

The main goal is to allow an accurate 1D simulation of the unsteady flows and the wave action along the intake and exhaust systems, without resorting to over-simplified geometrical discretization, and to rely on advanced thermodynamic combustion models for the calculation of cylinder-out emissions. The simulation of the aftertreatment systems is then performed resorting to a steady state model including a detailed chemistry approach, which allows an accurate prediction of the conversion of pollutant emissions under the typical wide range of operating conditions of a driving cycle.

With regard to the simulation of the transient vehicle dynamics during a WLTP cycle, this has been carried out by the code velodyn, which generated also the sequence of requested torque values to be provided 
by the IC engine. These data have been used as an input for the $1 D$ code engine simulation, to achieve an effective transient of the virtual engine coupled with its turbocharger and after-treatment system.

The effect of heat transfer between ambient air and exhaust pipes, including the AT system, has been included in the simulation of the engine coupled to the vehicle during the WLTP cycle. This is very important to predict correct gas temperatures at the inlet of the catalytic converters, which is fundamental for the calculation of the conversion efficiency of pollutant emissions.

This co-simulation environment has been validated against a real engine configuration, which was tested at the experimental labs of EMPA research center. An SI, 4-cylinder, turbo-charged, CNG engine has been simulated initially at different loads and speeds; the results have been compared with experimental measurements, to verify the prediction of engine performance and pollutant emissions. The validated virtual engine model has then been applied to carry out the prediction of IC engine performance, emissions and ATS activity during the WLTP driving cycle, highlighting the conversion efficiency of pollutants.

\section{Methodology}

In this work the gasdyn code, developed by the authors in collaboration with Exothermia, was used to model the unsteady reacting flows in the intake and exhaust systems of the engine, including the transport of the chemical species, whose concentration is evaluated by means of multizone thermodynamic combustion models. The main features of the numerical code have been described in previous works [11-16]. It allows for a detailed analysis of the fluid dynamic, thermal and chemical behaviour of the whole engine system.

For the purpose of this work the 1D model has been coupled to the ATS code, which is able to deal with any reaction scheme and rate expressions ("elementary" and "global" reactions) [17,18,19]. The ATS code allows 1D, 2D or 3D discretization at the device level and OD, 1D and quasi-2D in the wall direction, used when wash-coat diffusion limitations need to be accounted for. The ATS model adopted in this work exploits the assumption of simplified single channel. In this context the calculation of the gas temperature and species concentrations in the channel is based on the solution of the steadystate equations for the gas phase heat and mass transfer coupled to the transient characterization of the energy balance of the solid phase.

In this framework the model considers at surface level no accumulation of chemical species, assuming that everything that diffuses to the wash-coat reacts on it. The final balance of solid phase is taken into account by solving the energy conservation equation, also accounting for the transient behavior:

$$
\rho_{s} C_{p, s} \frac{\partial T_{s}}{\partial t}=\lambda_{s} \frac{\partial^{2} T_{s}}{\partial z^{2}}+S h\left(\frac{S}{1-\varepsilon}\right)\left(T_{g}-T_{s}\right)+\left(\frac{1}{1-\varepsilon}\right) \sum_{k=1}^{n_{k}} \Delta H_{k} R_{k}
$$

which considers the contribution of convective heat transfer of the gas flow in channels and of the heat released or adsorbed by chemical and adsorption reactions [20].

\section{D-ATS code coupling strategy}

To carry out a detailed simulation of the after-treatment system, the $1 D$ code has been coupled to ATS code. This type of approach, where

Page 2 of 13 codes specifically developed to simulate different processes are integrated within the same framework, has been adopted by other authors in the literature, each one with its own peculiarities and assumptions, but with the common target to achieve a realistic and fast simulation of engine transient cycles where the engine is controlled by an ECU [6-10]. In this work, since the numerical approaches of the two codes are different, the authors have developed a hybrid coupling to allow an unsteady approach and a steady-state one coexist in the same simulation framework. The main target of the developed strategy is to preserve the unsteady nature of the flow, with the propagation of

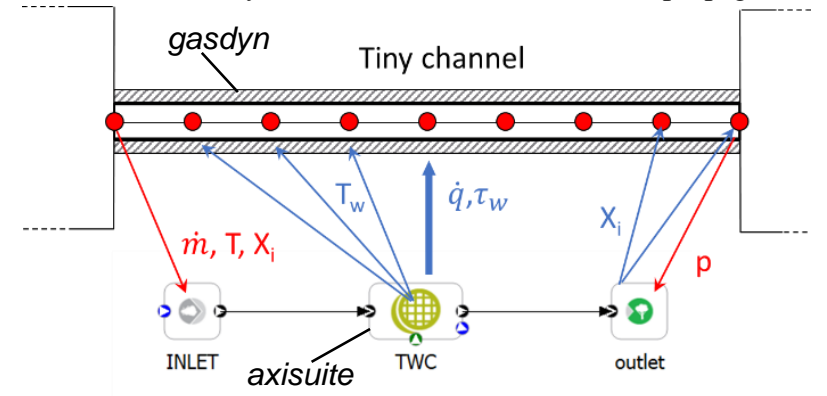

pressure pulsations, while exploiting the detailed calculation of the chemical reactions provided by the steady-state solver. To achieve this goal the coupling approach is based on the duplication of the catalyst element, by generating two overlapping elements that are solved in parallel and suitably merged in the final solution.

Figure 1. Schematic of the strategy adopted to couple the $1 D$ code with the ATS code.

The wave motion and the flow pulsations are predicted by $1 D$ code. Then, the passage of values from $1 D$ code to ATS code relies on the averaging of mass flow, gas temperature and chemical composition along a single (or a fraction of) thermodynamic cycle. These averaged pipe quantities, as shown in Figure 1, are assigned as inlet boundary conditions to ATS code. In this framework, the time step used for the integration of the steady state problem is larger than the time step used in $1 D$ code, which is subject to the CFL stability condition. Therefore, during the ATS code time step, quantities are integrated at the inlet and then used to perform the steady state calculation, when the cumulative time step of $1 D$ code has reached the ATS code one. Once ATS code has performed its time step, the solution is then mapped back to $I D$ code, transferring the quantities referred to the chemical activity and to the fluid dynamic processes occurring inside the catalyst: the wall temperature calculated node by node, the gas-wall heat flux at every node, the friction factor and the outlet species concentrations. The heat flux and the friction factor are then considered in $1 D$ code as source terms in the governing equations and they are fully integrated in the stencil of the numerical method. The outlet concentration of chemical species is overwritten to the concentration tracked by $1 D$ code. This can be realized only with the option of constant thermo-physical properties implemented in the $1 D$ code solver: the $c_{p}$ and molecular mass of the gas are considered constant regardless of the changes in the gas composition. The outlet concentration of ATS code is assigned to the last and second last node of the $1 D$ code domain and then passed as a zero-gradient trend to the characteristic-based approach. This allows to advect the desired concentration along the path lines and track it downstream of the catalyst, following the pulsations of the gas flow. 


\section{Combustion and pollutant emission models}

In order to have an accurate prediction of the engine fuel consumption and pollutant emissions, the first requirement is a detailed description of the occurring combustion process. When the industrial or research focus is on the prediction of the driving cycle tests, the engine performances at the steady bench have often already been measured for several operating conditions and possibly for the entire map. If the cylinder pressure traces have been acquired, then it makes sense to use such information and impose the burning rates derived from it for all operating conditions. Of course, since the real driving tests will include much more operating points than those acquired at the steady bench, it is required to fit such measured data into Wiebe functions, whose parameters depend on the engine operating conditions. In this work a so-called double-Wiebe function [21,22] was used, since a conventional single Wiebe approach would have not been able to accurately describe the different phases of combustion which were observed in this engine:

$$
\begin{gathered}
X_{b}(\theta)=\beta \cdot\left\{1-\exp \left[-a_{1}\left(\frac{\theta-\theta_{i 1}}{\theta_{f 1}-\theta_{i 1}}\right)^{m_{1}+1}\right]\right\}+ \\
+(1-\beta) \cdot\left\{1-\exp \left[-a_{2}\left(\frac{\theta-\theta_{i 2}}{\theta_{f 2}-\theta_{i 2}}\right)^{m_{2}+1}\right]\right\}
\end{gathered}
$$

In (6) the parameters to be determined are $a_{1}, a_{2}, m_{1}, m_{2}, \beta, \theta_{i 1}, \theta_{i 2}, \theta_{f 1}, \theta_{f 2}$. But they can be reduced through some considerations and assumptions:

- complete combustion: $a_{1}=a_{2}=6.908$;

- $\quad$ start of combustion is still corresponding to $X_{b}=0.01$ : $\theta_{i 1}=\theta_{i 2}=\theta_{X_{b}=0.01}$;

- $\quad$ end of combustion $\theta_{f 2}=E V O$;

- $\theta_{i 1} \leq \theta_{f 1} \leq \theta_{f 2}=E V O$;

- $\quad 0 \leq m_{1}, m_{2} \leq 5$

- $0 \leq \beta \leq 1$.

Since the start of combustion has been set as a function of a chosen value of burned mass fraction, this procedure is fully independent from the spark timing; if this information is available it can be used as $\theta_{i}$.

The $1 D$ code is able to predict the concentration of the main chemical species during the combustion process and their concentration in the exhaust gases discharged by cylinders at EVO. In particular, the combustion model adopts an equilibrium approach [23] to evaluate the concentrations of the major species $\left(\mathrm{H}_{2} \mathrm{O}, \mathrm{H}, \mathrm{H}_{2}, \mathrm{CO}, \mathrm{CO}_{2}, \mathrm{O}, \mathrm{O}_{2}, \mathrm{OH}\right.$, $\mathrm{N}_{2}$, NO). With regard to nitric oxides, the extended 6 reaction Zeldovich [24,25] is used to predict the kinetically controlled NO formation process, while the Baruah semi-empirical method is applied to estimate the carbon monoxide concentrations [26]. Additional submodel are employed for the unburned HC [27-32], taking account of the hydrocarbons released by the top land crevice and by the oil film.

\section{Test case}

The first step of the performed testing activity consists in the definition in the 1D code of all geometrical and operating information, including the turbocharger group, the air cooler and the after-treatment systems
(Figure 2), which were described in the ATS code, with the schematic of the representation of a single channel.

In this study a light duty 3.0L SI, NG, turbocharged engine was considered. The engine is fuelled by Natural Gas (NG), which is injected inside the primary ducts by a Port Fuel Injection (PFI) system, adopting a sequential and phased strategy. The engine is supercharged by means of a turbocharging group with a single stage Fixed Geometry Turbine (FGT) and a Wastegate (WG). In the induction system an intercooler is adopted, in order to increase the volumetric efficiency and to reduce the knocking propensity. Three catalytic converters are located downstream of the turbine: one pre-cat, based on a metallic support, one ceramic main catalyst and a third monolith, not loaded with precious metals.

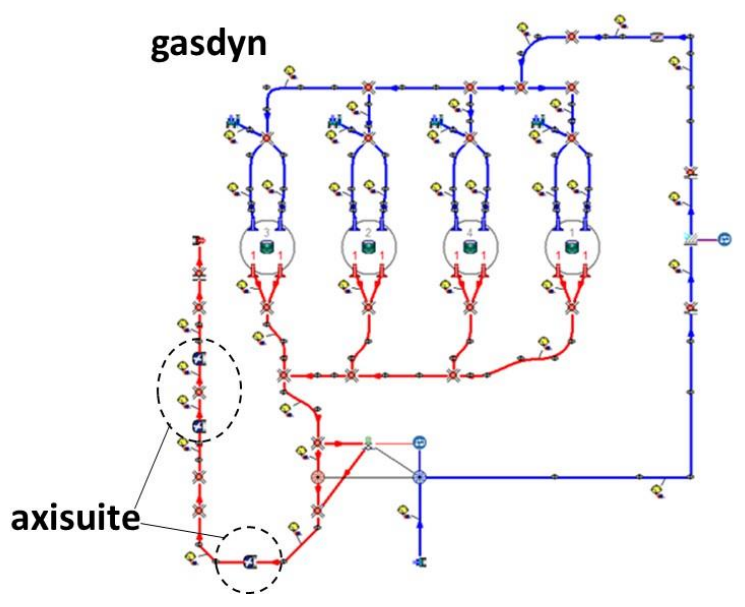

Figure 2. Schematic of the light duty 3.0L SI NG turbocharged engine realized by means the graphical interface gasdynPre.

This engine has been instrumented and investigated experimentally on the test bench at EMPA labs, to study and optimize the combustion process and reduce the pollutant emission formation. The experimental campaign has been carried out on the engine where its serial-production Engine Control Unit (ECU) has been replaced with a rapid-prototyping ECU with in-house coded functionalities. Additionally, since the original exhaust system was originally developed for a Diesel engine, the ATS system has been adapted to operate when coupled to a SI engine keeping a layout as much as possible close to the original one. For this reason the CRT unit has been replaced with a TWC, with the functionality of an underfloor catalyst and an uncoated ceramic brick, which serves as strengthening of the structure (with respect to leaving the space empty). A post turbine precat TWC has been added with the purpose of reducing the light off time. The precat is made of a metallic substrate (400cpsi $/ 1.6 \mathrm{mils}$ ) with a volume of $0.65 \mathrm{~L}$ and a loading of $250 \mathrm{~g} / \mathrm{L}$, whereas the main TWC is a ceramic based monolith (400cpsi/4mils) ,around 2 litre of volume and a loading of $70 \mathrm{~g} / \mathrm{L}$.

\section{Engine modeling}

The 1D model was initially used to generate static maps expressing fuel consumption and pollutant emissions as a function of engine speed and load. 3 PID controllers on turbine wastegate, intercooler and throttle valve were used. The information contained in the EMPA dataset include fuel consumption, torque, pollutant emissions, boost pressure and several further experimental data for each operating point represented in Figure 3. However, the in-cylinder pressure trace as function of crank angle was available only for the 52 points inside the 
red boxes. Hence, only these points will be considered in the present analysis.

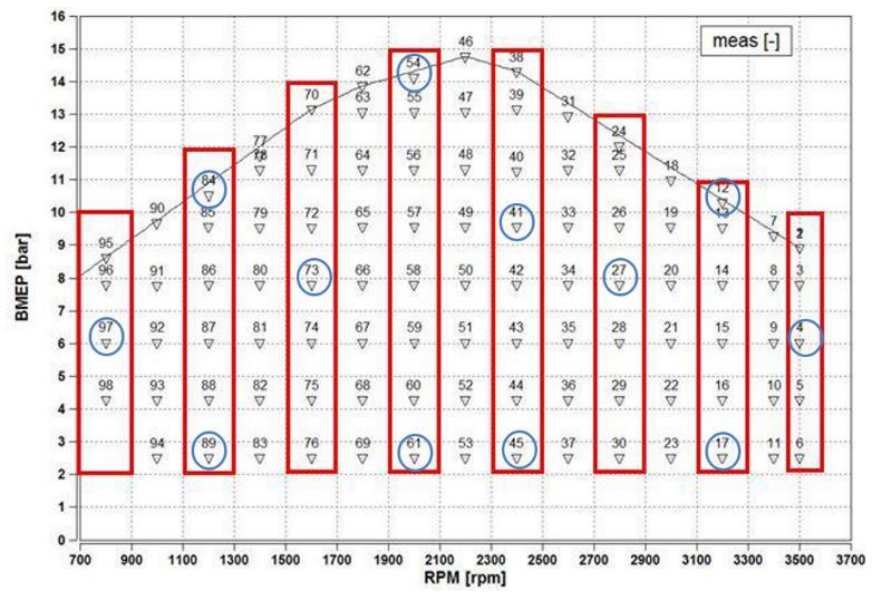

Figure 3. Measured operating points on the engine maps; red boxes show the availability of the pressure signal as a function of crank angle, blue circles the selected 12 points

Simulations were run using the optimal set of double-Wiebe parameters and the 52- and 12-point interpolation functions. In Figure 4 the scatterplots and the corresponding linear regression plots of the angular position for which half of the fuel mass is burned $\left(\theta_{50}\right)$ and the duration of combustion $\left(\theta_{10 \_90}\right)$ are reported together with the regression coefficient $R$. It is evident that a very accurate prediction of the $\theta_{50}$ was achieved, while even using a double-Wiebe function there are several operating points for which the description of the measured burning rate is not so accurate. An example of a point for which the accuracy is good for the entire combustion (point 23, Fig. 3) and another one for which the accuracy is weaker (point 40, Fig. 4) is shown in Figure 5.
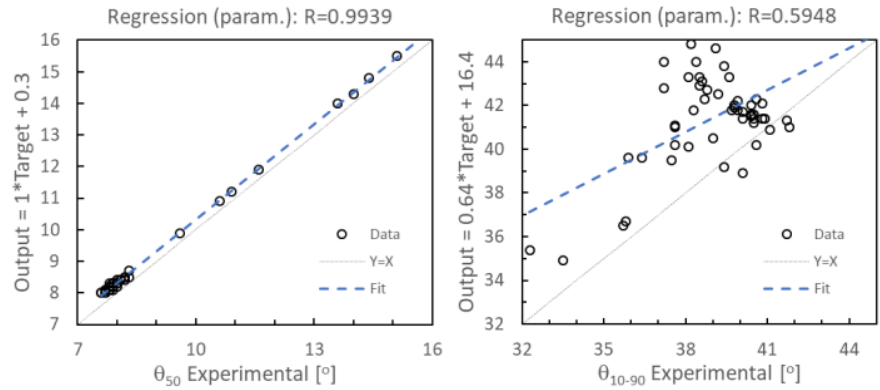

Figure 4. Scatterplots and linear regression plots of $\theta_{50}$ and $\theta_{10_{-} 90}$ using the optimized parametrization of the double-Wiebe function.
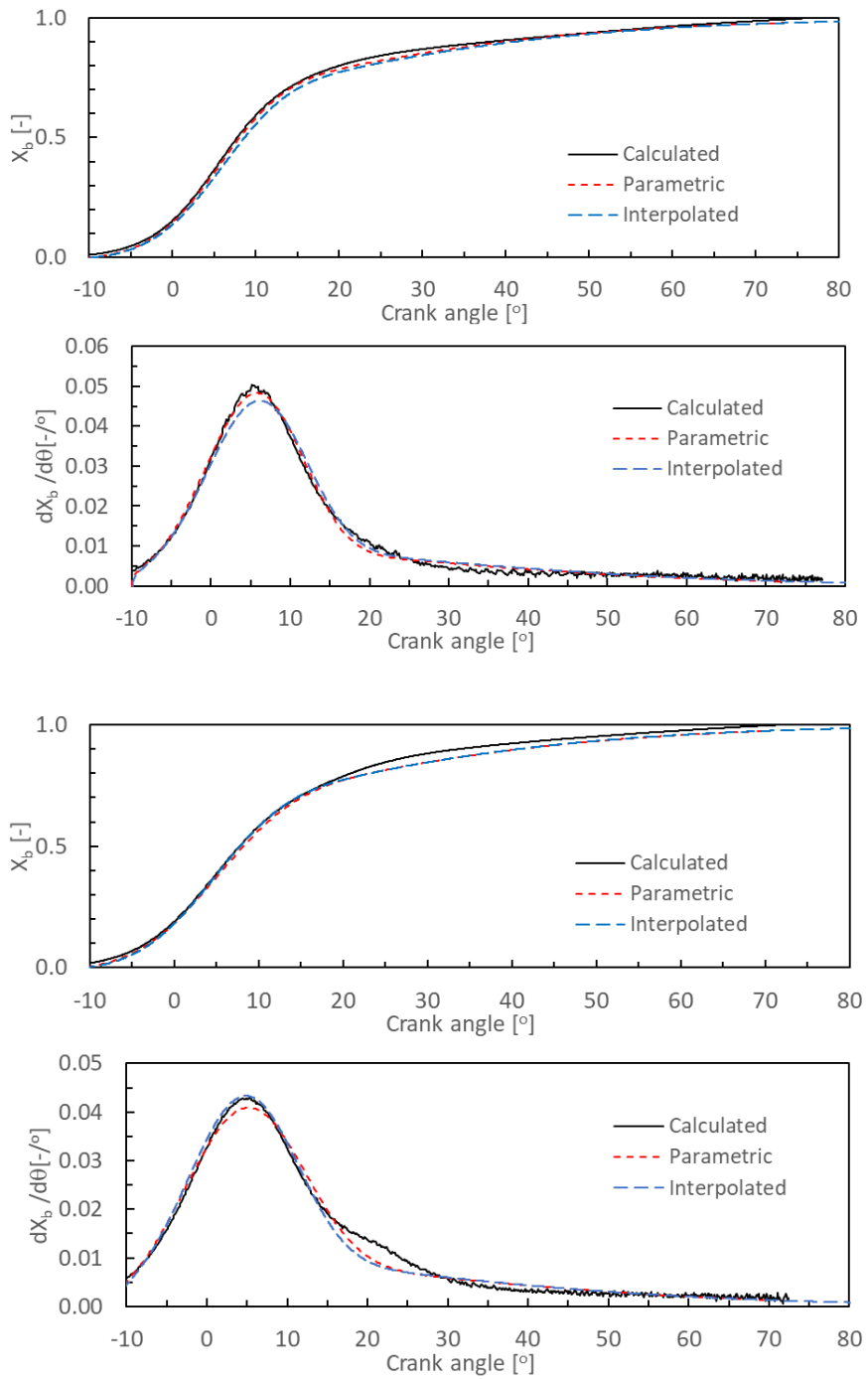

Figure 5. Two examples of comparison between calculated curves and the corresponding outcome of the interpolation.

Moreover, in order to evaluate the complete set of double-Wiebe parameters for every possible combination of engine speed and load, a fifth-degree and a third-degree polynomial expression using respectively 52 and 12 operating points was determined for each parameter, choosing the engine speed and volumetric efficiency as independent variables. Figure 6 shows the scatter and the linear regression plots $\theta_{50}$ and $\theta_{10 \_90}$ with the interpolation of the Wiebe parameters using 52 and 12 operating points. It can be observed that a good accuracy is achieved, which make the proposed methodology applicable for any possible engine operating point, hence also to simulate the transient conditions of a driving cycle. 

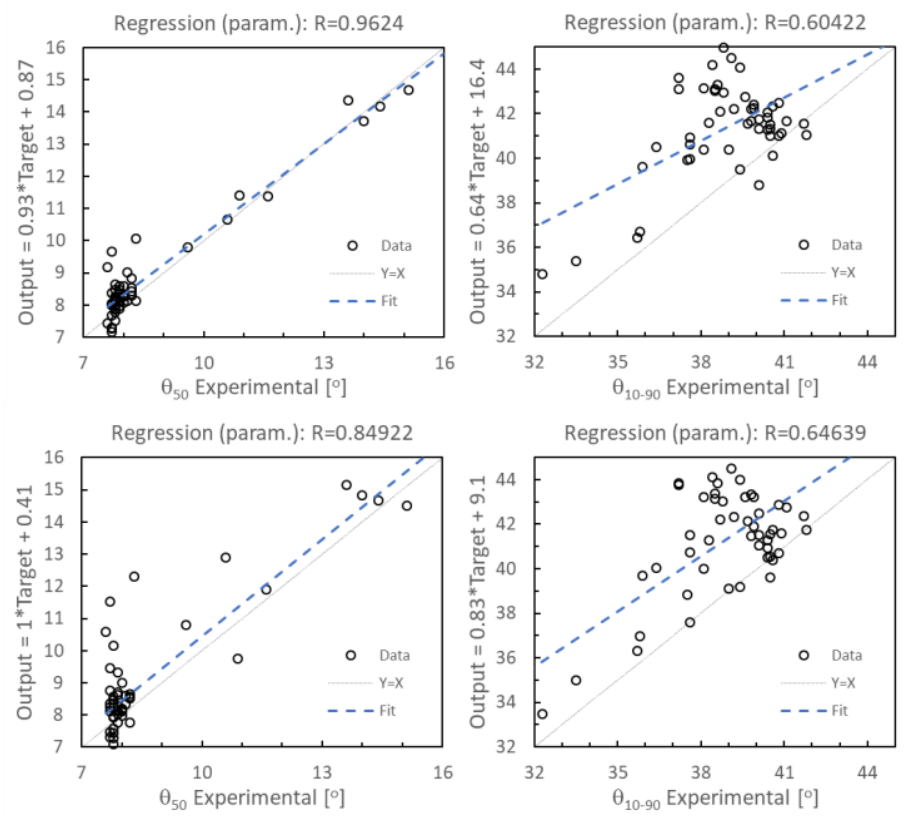

Figure 6. Scatterplots and linear regression plots of $\theta_{50}$ and $\theta_{10 \_90}$ using the interpolations with 52 and 12 operating points respectively.

\section{Steady maps of fuel consumption and in-cylinder emissions}

Each operating point resulting from the simulation with $1 D$ code must be characterized by the same $B M E P$ (used as load parameter) and the same engine speed of the corresponding operating point coming from the experimental dataset. For what concern the fuel consumption, for each simulated operating point, the specific fuel consumption in $\left[\frac{g}{k W h}\right]$ that was compared with the same quantity that is available in the experimental data and Figure 7 shows the percentage error across the entire map of BSFC of the $1 D$ code simulation versus the experimental data. The error is generally below $2.6 \%$, with the only exception represented by those points with a very low $B M E P$.

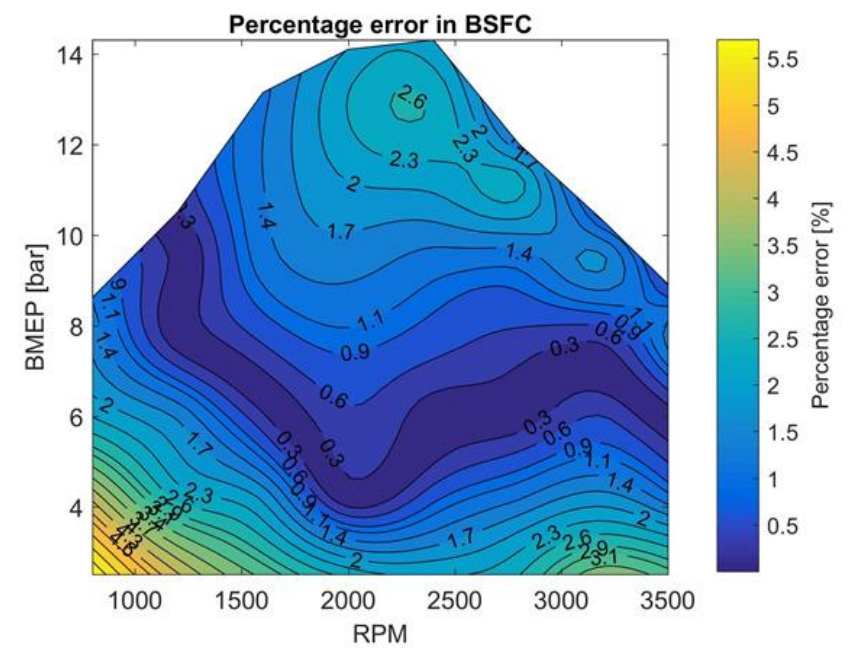

Figure 7. Percentage error across the map of BSFC of the $1 D$ code simulation versus the experimental data.

Figure 8 shows the percentage error across the map between $\mathrm{NO}_{\mathrm{x}}$ of the $1 D$ code simulation versus the experimental data; in the majority

Page 5 of 13 of the map the error is less than $5.3 \%$ that is a good result, while in the bottom right corner a larger error is present. This behaviour is probably due to a combination of errors in the estimation of the thermal losses and the progress of $\mathrm{NO}_{\mathrm{x}}$ reduction reactions at low load and high engine speed. However, this area of the engine map is obviously of not great relevance.

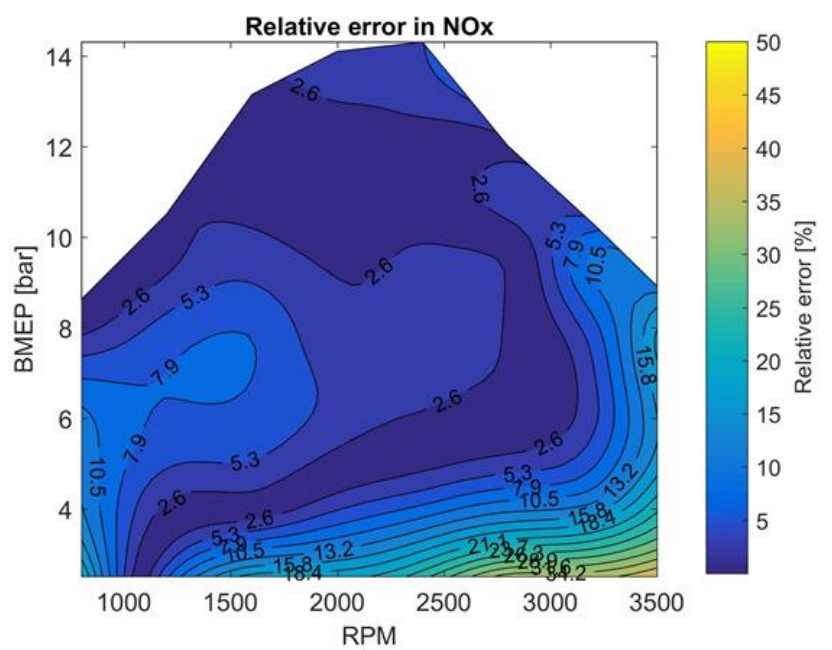

Figure 8. Percentage error across the map of $N O_{x}$ of the $1 D$ code simulation versus the experimental data.

Also the CO map has been determined and compared with the experimental values as percentage error as shown in Figure 9, but results are not as good as for nitric oxides. Probably the main reason is that the engine was not experimentally operated in closed loop control, so minor deviation from the stoichiometric target values might occur. This has a strong impact in terms of relative error on the in-cylinder $\mathrm{CO}$ concentration than NO.

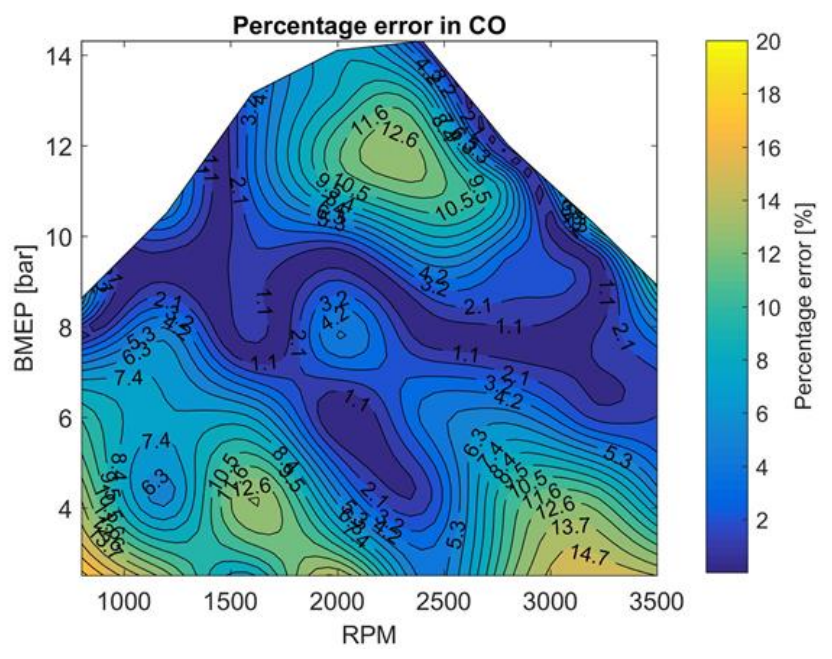

Figure 9. Percentage error across the map of $C O$ of the $1 D$ code simulation versus the experimental data.

To achieve a good evaluation of unburned hydrocarbon $(H C)$ emissions, a tuning procedure is required to calibrate mainly the crevice and the incomplete combustion contributions. The first contribution was set using as reference the experimental data of point number $2(3500 R P M, B M E P=7.79 \mathrm{bar})$, for which a complete combustion was assumed. The second contribution was included for 
the operating points with an engine speed lower than $1200 \mathrm{rpm}$. The corresponding tuning was carried out acting on the efficiency parameter $a_{2}$, with a trial and error process (after having set the right crevice values), using as reference the experimental data of $\mathrm{HC}$ emissions of points 44 and 49 (1200 and $800 R P M$ respectively, both with $B M E P=7.79 \mathrm{bar}$ ). The result achieved in terms of relative error for the HC emission is shown in Figure 10. It is evident that it does not have the same value in terms of predictiveness as for NOx and CO emissions, however it allows the $1 D$ model, after calibration, to simulate any operating point on the engine map, so that the engine model can be applied for vehicle simulations of driving cycles.

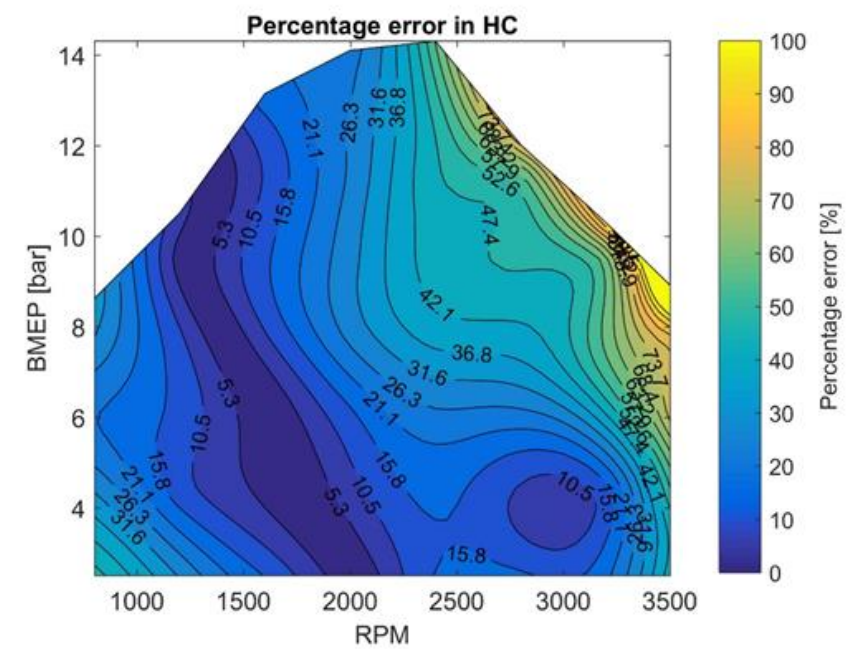

Figure 10. Percentage error across the map of $H C$ of the $1 D$ code simulation versus the experimental data.

\section{Tail pipe emissions at steady operating conditions}

The coupling between $1 D$ code and ATS code has been used at this point for the prediction of the tailpipe pollutant emissions. To this purpose not all the points of the map have been simulated, since the calculation of the ATS efficiency must be carried out taking into account the thermal transient of the catalytic converters. This is due to the fact the temperature level of the reacting substrates is a consequence of the balance between the heat released by the exothermal reactions, the heat exchanged between the gas and the catalyst wall and the heat losses with the surrounding environment. Hence it is necessary to carry out the simulation of the thermal transient of the three catalysts with different thermal capacity, given mainly by the difference of material and size. The average simulation time to complete the transient, for this particular configuration, is around 100 seconds of real time. Even starting with a suitable initial condition, that can be guessed by the measured gas temperature at the inlet and outlet of the ATS, this involves the simulation of thousands of thermodynamic cycles, depending on the engine revolution speed, resulting in a large computation time. For this reason only a set of fixed operating points have been simulated, namely a sweep of engine speeds at a fixed BMEP (7.79) and sweep of loads at a fixed engine speed (2000 rpm).

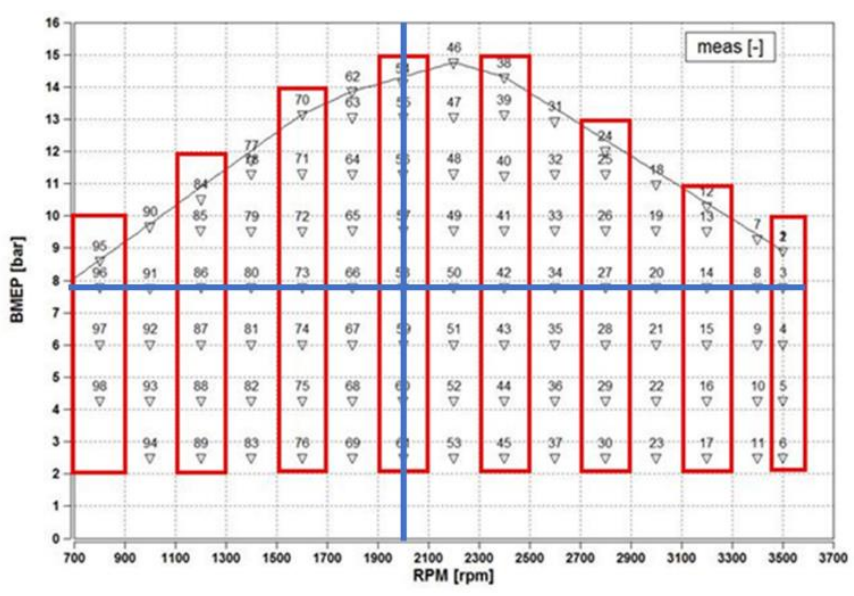

Figure 11. Selection of operating points used for the validation of the calculated ATS performance.

The selection of operating conditions is shown in Figure 11. Further points of the same engine have been simulated and discussed in a previous publication, where the study focused on the full load condition [20]. The catalytic converters adopted in this exhaust system are typical TWC for SI engines; despite the geometrical parameters of the three catalysts were fully known, the chemical composition of their washcoats was guessed on the basis of typical catalyst properties, since the manufacturer did not provide complete information about them. Therefore, these devices have been modelled exploiting the predefined chemical libraries of ATS code for the simulation of three-way catalysts. In particular, the set of reactions considered is the following one:
1. $\mathrm{CO}+0.5 \mathrm{O}_{2} \rightarrow \mathrm{CO}_{2}$
2. $\mathrm{H} 2+0.5 \mathrm{O}_{2} \rightarrow \mathrm{H}_{2} \mathrm{O}$
3. $\mathrm{CH}_{4}+2 \mathrm{O}_{2} \rightarrow \mathrm{CO}_{2}+2 \mathrm{H}_{2} \mathrm{O}$
4. $\mathrm{CO}+\mathrm{NO} \rightarrow \mathrm{CO}_{2}+0.5 \mathrm{~N}_{2}$
5. $\mathrm{H}_{2}+\mathrm{NO} \rightarrow \mathrm{H}_{2} \mathrm{O}+0.5 \mathrm{~N}_{2}$
6. $\mathrm{CH}_{4}+\mathrm{H}_{2} \mathrm{O} \rightarrow \mathrm{CO}+3 \mathrm{H}_{2}$
7. $\mathrm{CO}+\mathrm{H}_{2} \mathrm{O} \leftrightarrow \mathrm{CO}_{2}+\mathrm{H}_{2}$

The model accounts for the competition between chemical species at the active sites of the washcoat by means of Langmuir-Hinshelwood inhibition terms.[33] Additionally, the sub-model for oxygen storage has been considered, to account for eventual fluctuations of the cylinder feeding conditions. The results of the simulation at constant BMEP and variable engine revolution speed are shown in Figure 12. 

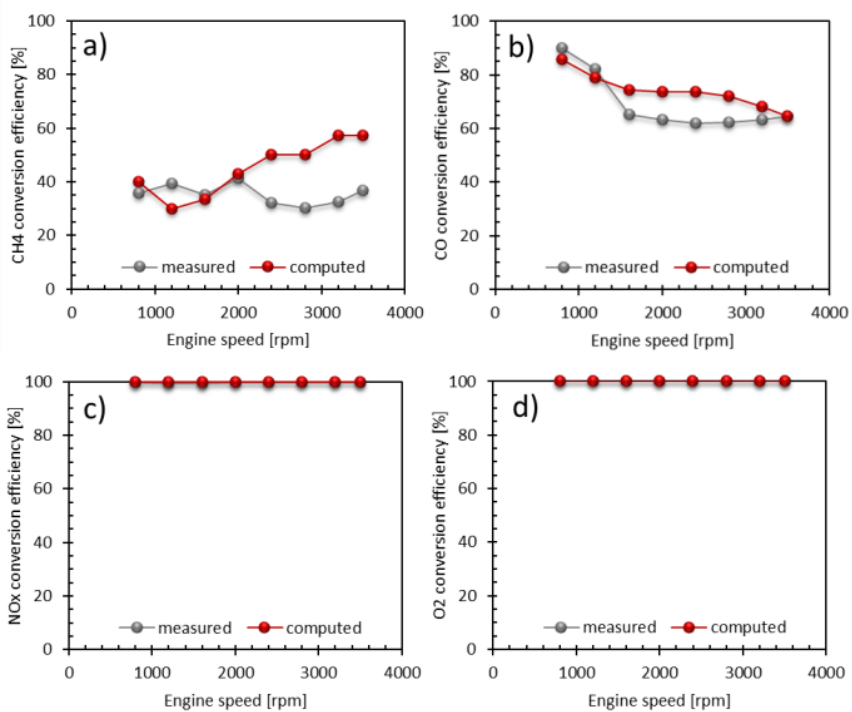

Figure 12. Experimental and calculated a) $\mathrm{CH} 4$, b) $\mathrm{CO}$, c) $\mathrm{NOx}$ and d) $\mathrm{O} 2$ conversion efficiency across the whole ATS: at BMEP=7.79 bar

Figure 12 shows the abatement efficiency of $\mathrm{CH}_{4}, \mathrm{CO}$ and $\mathrm{NO}_{x}$ plus the consumption of $\mathrm{O}_{2}$. The model predicts with fair agreement the abatement of the main pollutants. It must be said that the properties of the catalytic converters were not fully known. More specifically only the geometrical parameters of the substrates and the washcoat were specified, whereas the chemical composition of the washcoat itself was guessed on the basis of typical values of metallic and ceramic based catalysts. Figure 12 highlights the complete consumption of $\mathrm{O}_{2}$ by the kinetics of all the oxidation reactions, such as the oxidation of $\mathrm{CH}_{4}$ and $\mathrm{CO}$. The complete reduction of $\mathrm{NO}_{\mathrm{x}}$ is realized by ceria oxides in regions where the presence of oxygen is weak. Despite the slightly lean feeding condition, the oxidation of $\mathrm{CH}_{4}$ does not occur in a complete way. This in mainly due to the slow kinetics of methane, which requires high residence time and a sufficient level of temperature. Moreover, also CO seems not to be oxidised, even in lean conditions. The cause of this inefficiency resides in the effect of the steam reforming reaction, which converts the $\mathrm{CH}_{4}$ with water to produce $\mathrm{CO}$ and hydrogen [34,35]. This explains the overestimation of the $\mathrm{CH}_{4}$ abatement and the consequent low abatement efficiency of carbon monoxide. The kinetics of this reaction has been taken as a default value of the ATS code library without any calibration.

With regard to the fluid dynamic analysis, Figure 13 points out that the prediction of the gas temperature at the inlet of the ATS is coherent with the measured one, for all the engine revolution speeds examined at BMEP equal to 7.79 bar. The prediction of the gas temperature at the inlet of the ATS is important to match the correct thermal level of the catalysts, which is the main driver of the reaction kinetics. This has been achieved with fairly good accuracy, as can be seen in
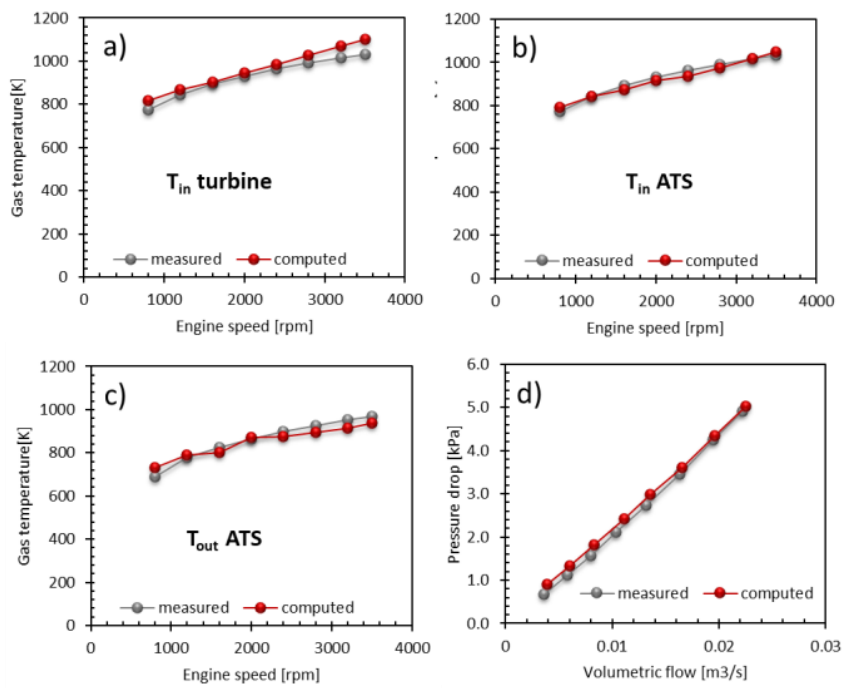

Figure 13. Comparison between measurements and calculated values: a) gas temperature before the turbine, b) gas temperature at the inlet of the ATS, c) gas temperature downstream at the outlet of the ATS d) pressure drop of the ATS.

Figure 13.b, where the error is within the $3 \%$ with respect to the measured values. This has been possible thanks to the correct calculation of the gas temperature at EVO and of heat transfer in the exhaust manifold, as can be seen in Figure 13.a, where the calculated temperature at the turbine inlet is compared with the measured one. Then the matching of the turbocharger operating conditions allows to evaluate correctly the outlet gas temperature. This also is supported by the calculation of the pressure drop across the whole ATS as a function of the volumetric flow; Figure 13.d shows that the experimental trend and the calculated one are in good agreement. Only a slight change in the curve slope can be noticed, which is likely due to the $1 \mathrm{D}$ assumption adopted for the modelling of the tiny channels of the substrate. Figure 13.c shows the comparison between the calculated and measured gas temperature at the outlet of the ATS. This temperature is the result of the chemical activity inside the two catalysts and represents an index of the accuracy of chemistry prediction. It appears to be under-predicted at engine speeds higher than $2000 \mathrm{rpm}$, probably due to an overestimation of the methane steam reforming step, which is an endothermic reaction.

Similar considerations can be done for the operating points at fixed engine speed and different BMEP shown in Figures 14 and 15. The quantities predicted and compared with the experimental data are the same of the previous Figures 12 and 13. In this last case, for what concerns the prediction of pollutant emissions, it can be seen that the $\mathrm{CH}_{4}$ calculation is less affected by the overestimation of the steam reforming reaction rate. Similar trends can be observed in the case of $\mathrm{CO}$ emissions, where $\mathrm{CO}$ is consumed thanks to the availability of oxygen, due to the slightly lean $\mathrm{A} / \mathrm{F}$ ratio. $\mathrm{NO}_{\mathrm{x}}$ and $\mathrm{O}_{2}$, as can be seen from Figures 14.c and 14.d, are completely consumed in agreement with the measurements. Also in this case the fluid dynamics is well predicted, showing that the gas temperature before the turbine, downstream of the turbine and downstream of the ATS are calculated with an acceptable approximation (Figure 15.a, 15.b and 15.c). This, once again, allows to achieve a correct temperature level for a realistic prediction of both chemistry and back pressure. The validation carried out in these steady state conditions will be further extended in the following section concerning the simulation of a driving cycle, namely 
the WLTP, to calculate the emission levels considering the thermal transient of the whole exhaust system. The WLTP cycle will be simulated by imposing the torque output to the engine at every thermodynamic cycle, on the basis of the torque calculated by the coupling between the $1 D$ code and the vehicle dynamics code..
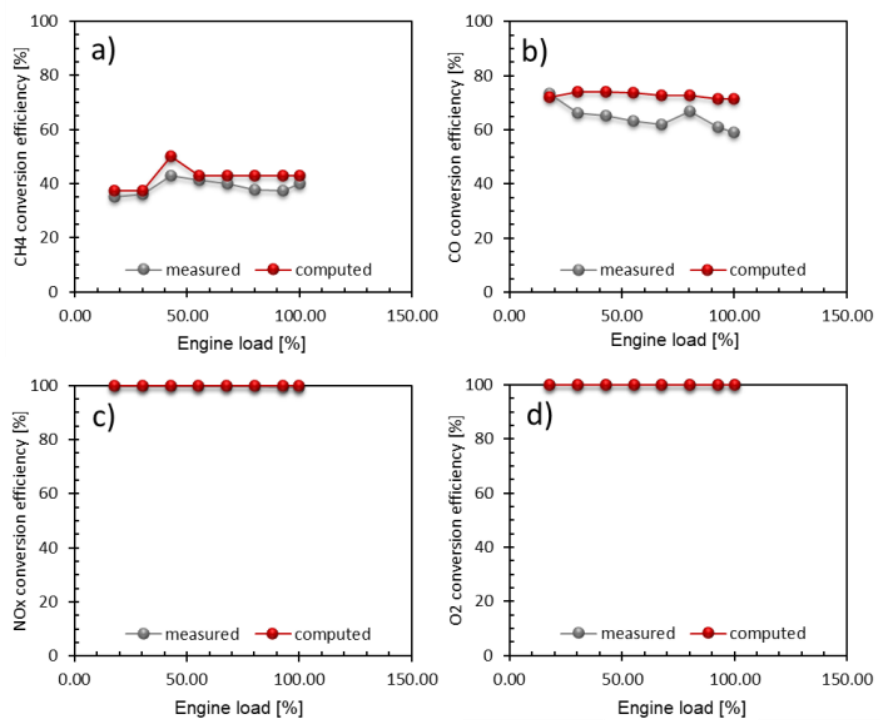

Figure 14. Experimental and calculated a) $\mathrm{CH} 4$, b) $\mathrm{CO}$, c) $\mathrm{NOx}$ and d) $\mathrm{O} 2$ conversion efficiency across the whole ATS: at 2000 rpm for different BMEP values.
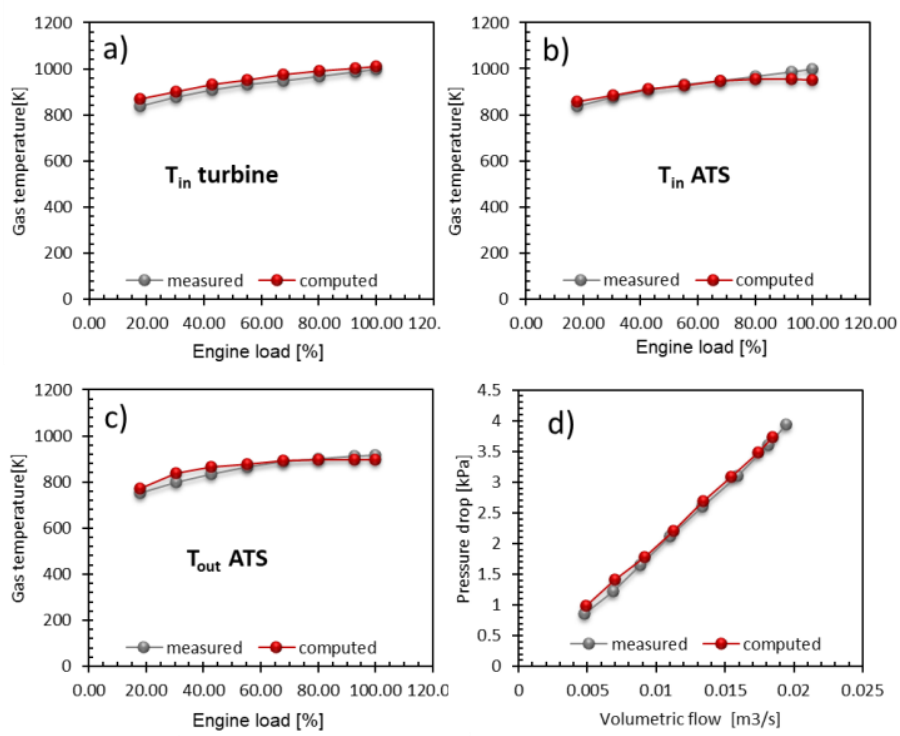

Figure 15: Comparison between measurements and calculated values: a) gas temperature before the turbine, b) gas temperature at the inlet of the ATS, c) gas temperature downstream at the outlet of the ATS d) pressure drop of the ATS.

\section{WLTP cycle simulations}

To perform the simulation of a driving cycle, the IAV velodyn software has been used [36,37]. This model allows to simulate of the vehicle dynamics and is based on an approach that can be considered as in between the Backward Quasi-static and the Inverse-Dynamic approaches $[4,38]$ : the way that the dynamics is accounted makes it near to the Inverse Dynamic approach, but the main components, like the engine, are still modelled as static maps. Two vehicle models were built, which are identical in all aspects except for the static maps the engine is modelled with. The first model uses experimental maps and is chosen as reference. For the sake of simplicity, this model will be named "Model 1". It features the torque map (indexed by throttle valve opening and engine speed) and the fuel consumption map (indexed by torque and engine speed) directly taken from experimental data. The second model (from now on "Model 2"), instead, is based on the performance maps computed by $1 D$ code using the double-Wiebe combustion model on the 52 points of operating conditions. The vehicle that has been used for the simulation is the Iveco Daily $35 \mathrm{~S} 14 \mathrm{NV}$.

The two different strategies have been compared in the context of the simulation of a WLTP cycle, where the only difference between the two approaches is the type of engine maps that is used, namely measured and calculated. Figure 16 compares the operating points of Model 1 and 2 in four different parts of the WLTP cycle: low velocity, medium velocity, high velocity and extra high velocity
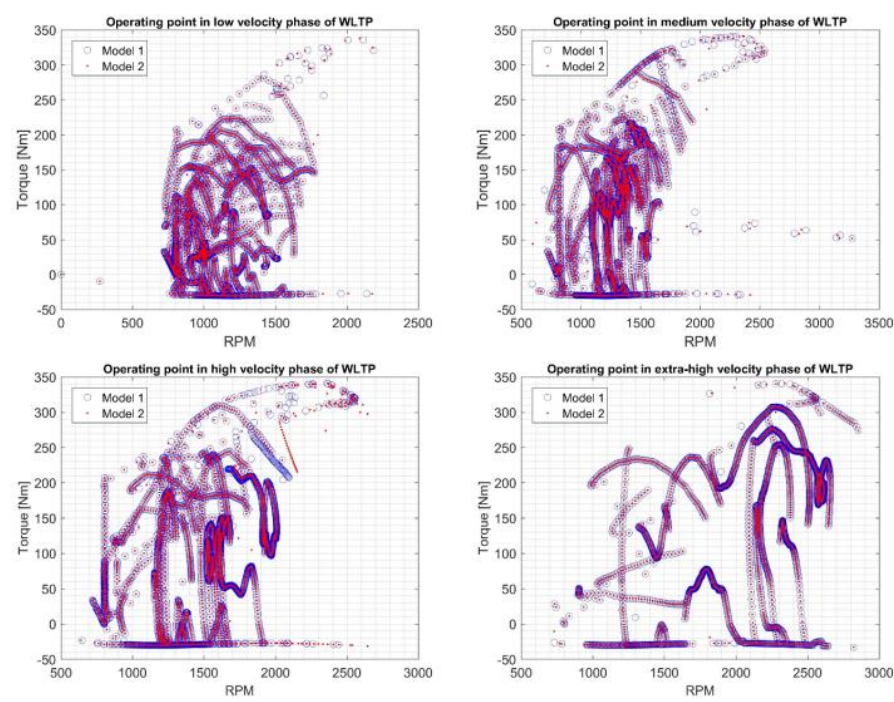

Figure 16. Operating point comparison in the four parts of the WLTP cycle simulated using Model 1 and Model 2.

As can be seen in Figure 16, apart from few points, the engine operating points, in terms of torque and engine revolution speed, used by the two models are coincident. This means that the engine with the simulated data of Model 2 works in almost every instant at the same operating point of the engine of Model 1. This result was expected, since the torque delivered by the simulated engine corresponds to that delivered by the measured engine of Model 1 for every combination of engine speed and throttle valve opening. Once it has been verified that in the two configuration the two models are delivering the same engine output, it is possible to compare the fuel consumptions of the two models 


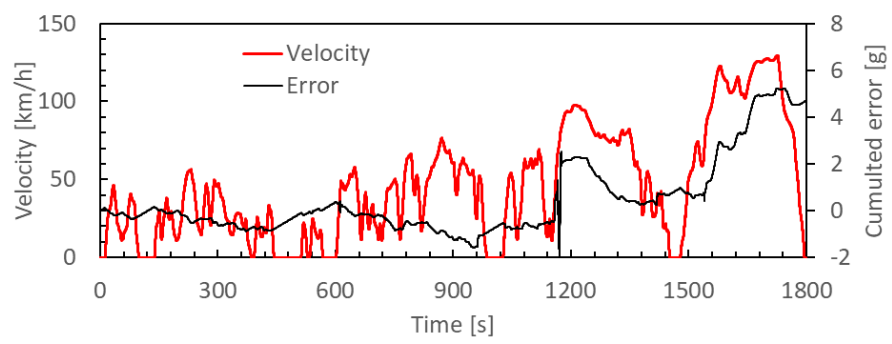

Figure 17. Cumulated error of Model 2 vs Model 1 as a function of time in WLTP cycle.

In the cumulated fuel consumption plot of Figure 17, it is possible to notice that the Model 2 tends to consume less fuel, compared to Model 1 , in those parts of the cycle that use mostly the bottom-left area of the engine map (low load and $R P M$ ), so the low velocity and the medium velocity parts of the cycle. The reason behind these zones with higher error lies in the choice of the points for the interpolation. In the high velocity region, and especially in the extra-high velocity part of the WLTP, there is an inversion of tendency that is linked to the operating points that are more and more in the right region. The result is a slight difference of less than $5 \mathrm{~g}$ of fuel, corresponding to a percentage error of $\sim 0.27 \%$.

The map-based approach that have been used to build Model 1 and Model 2, as it has been explained, is characterized by maps built up by steady state engine operating points. This is a rather strong assumption since an ICE, by nature, is an unsteady volumetric machine, whose performances in terms of torque, fuel consumption and pollutant emissions are heavily influenced by the unsteady phenomena occurring in the exhaust and intake systems, such as pipe thermal inertia and turbocharger inertia. The $1 D$ code software makes available two different ways to simulate an engine in transient operation, so that the effects neglected in the map-based approach can be captured. The first approach is the "vehicle transient" where all the data of a simple vehicle, which the engine is installed on, are considered. This also includes the transmission as well as the gear ratio and the engine speed at which the gear shift must occur. The driving cycle that must be followed can be imposed in terms of vehicle speed as a function of time. Two PID controller acting on the accelerator and the brake pedal are used to achieve the target speed represented by the driving cycle. The second option is the "engine transient" mode, where the vehicle is neglected and the required torque and engine speed along the WLTP are imposed as functions of time. In this case the engine speed is imposed, while a PID controller will modulate the throttle valve opening to achieve the target torque. The target torque profile and the engine speed trace used in the code are imposed exploiting the output of the vehicle simulation, using the Model 2 approach. In this way an indirect coupling between the vehicle dynamic code and the $1 D$ code was realized.

The WLTP cycle consists of several strong accelerations and decelerations and does not consider constant velocity sections. Consequently, the torque profile is characterized by several peaks, suggesting that the inertial effects are expected to have high impact on the results, much more than what happens in the NEDC cycle. Figure 18 compares the delivered torque by the two approaches to describe the WLTP cycle, where it is possible to see that the PID controller action permits to follow precisely the desired torque along the whole cycle.

Page 9 of 13

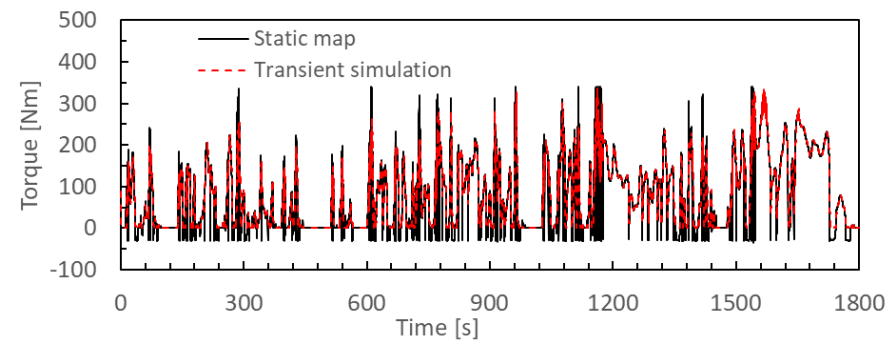

Figure 18. Engine delivered torque comparison between the two approaches in WLTP cycle.

Figure 19 compares the instantaneous fuel consumptions and the error that the simplification of the static map has when compared with a proper transient simulation. Of course, the highest errors correspond to the more demanding transient operations, nevertheless if we look at the cumulated fuel consumption curve, as shown in Figure 20, the final error is limited to $69.97 \mathrm{~g}$ which corresponds to $4 \%$.
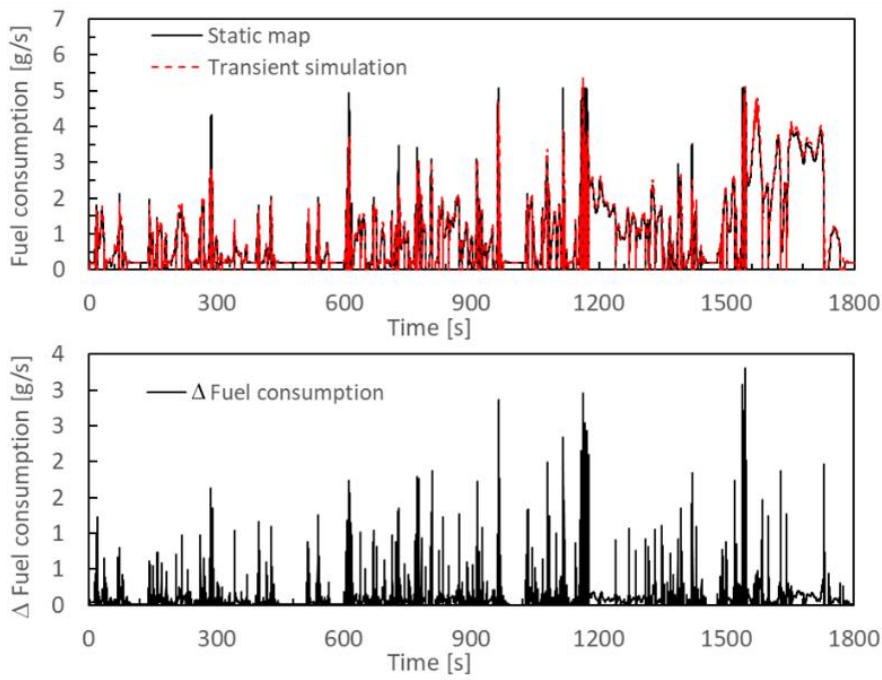

Figure 19. Fuel consumption of the two models and the instantaneous error of the static map approach vs the transient model in the WLTP cycle.
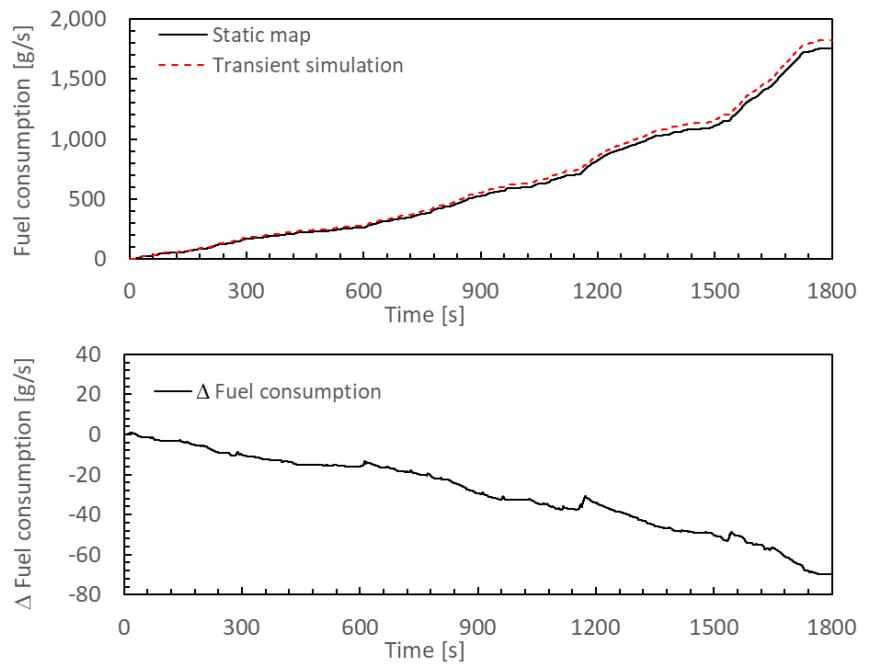

Figure 20. Cumulated fuel consumption and error between transient and map based approach in WLTP cycle.

In terms of tailpipe emissions, the simulation in "engine transient mode" allows to model the reacting flows occurring inside the ATS. 
As described in the previous section, the after-treatment unit is composed by two catalysts, one metallic precat and a ceramic main cat. The simulation of the ATS is carried out resorting to the coupling with ATS code, according to the coupling strategy previously described. The importance of this approach is that the fluid dynamics of the engine is fully preserved, even if the coupling is realized with a steady state solver. As a consequence, there is no impact on the simulation of the engine performance when the two codes are coupled.

The main outcome of the WLTP simulation is the estimation of the cumulative emission at the outlet of the ATS. This allows to evaluate the performance of the ATS and to state whether the actual calibration and setup of the engine is sufficient to comply with the emission regulation. In Figure 21 the cumulative emissions of $\mathrm{CH}_{4}, \mathrm{CO}$ and $\mathrm{NO}_{x}$ are shown. In agreement with what has been presented in the analysis of the ATS emissions at fixed operating conditions, the $\mathrm{NO}_{\mathrm{x}}$ emissions are very low. The main contribution to their emission comes from the first part of the WLTP cycle, when the engine is cranked and the exhaust system needs to reach the light-off temperature. This aspect is strongly linked to the materials and thickness of the exhaust pipes (meaning the thermal capacity).

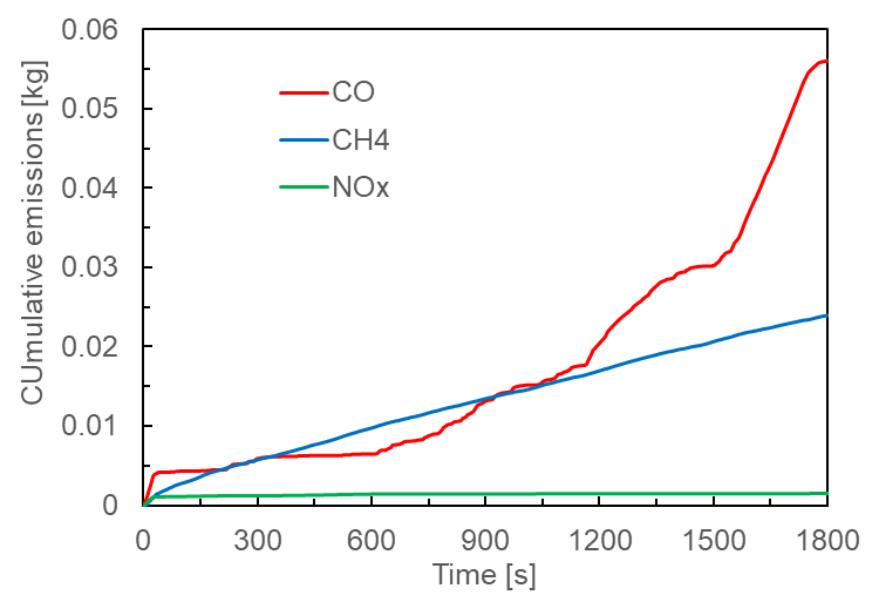

Figure 21. Calculated cumulative emissions of $\mathrm{CH}_{4}, \mathrm{NO}_{\mathrm{x}}$ and $\mathrm{CO}$ during the WLTP at the tailpipe.

On the contrary the emission levels of $\mathrm{CH}_{4}$ and $\mathrm{CO}$ are the major issue in this type of engine configuration, since the $\mathrm{CH}_{4}$ is affected by a slow kinetics, which requires higher residence time to perform high conversion. The $\mathrm{CO}$, instead, suffers the activation of the methane steam reforming reacting paths which increases the $\mathrm{CO}$ concentration in the gas stream. A better description of the conversion efficiencies reached during the WLTP cycle it depicted in Figure 22, where the abatement efficiency of $\mathrm{CH}_{4}, \mathrm{NO}_{\mathrm{x}}$ and $\mathrm{CO}$ are plotted as functions of the mass flow rate of the exhaust gas. It is evident that the $\mathrm{NO}_{\mathrm{x}}$ abatement is always high at every mass flow and at every gas temperature, whereas for the methane and the carbon monoxide the conversion efficiency depends on the mass flow rate and on the gas temperature and is always lower than $100 \%$. The region at low catalyst efficiency is related with the low temperature level of the exhaust gas that characterizes the cold start phase of the engine, or the phases when the engine accelerates after a period of idle condition. Points at the maximum mass flow are those characterized by the highest revolution speed and engine load (hence gas temperature) where it is possible to observe a lower conversion of $\mathrm{CH}_{4}$ and $\mathrm{CO}$ due to the reduced residence time in the catalyst.

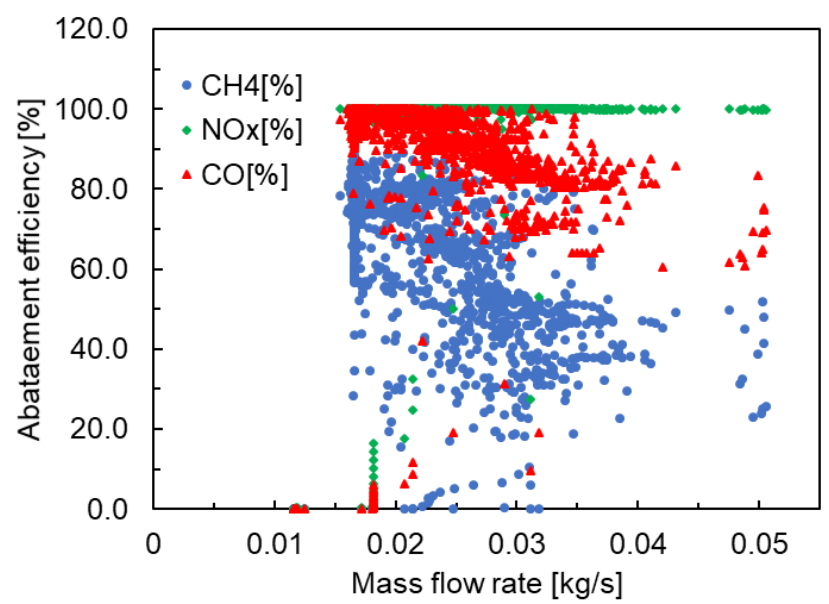

Figure 22. Abatement efficiency of $\mathrm{CH}_{4}, \mathrm{CO}$ and NOx during the WLTP cycle as function of the exhaust gas mass flow rate.

In Figure 23 the cloud of points relative to the driving parameter of the chemistry is represented. These two parameters are the mass flow and the gas temperature at the inlet of the ATS. The abatement efficiency is strictly linked to them since they determine the residence time in the catalysts and the temperature level of the substrate that appears in the exponential factor of the Arrhenius type expression of the reaction rate. From this graph it is possible to see that at similar exhaust gas mass flows the gas temperatures can be higher due to different turbocharger matching and exhaust system temperatures. This explains why the average conversion efficiencies of $\mathrm{CO}$ ad $\mathrm{CH}_{4}$ are higher than those calculated for the steady state points.

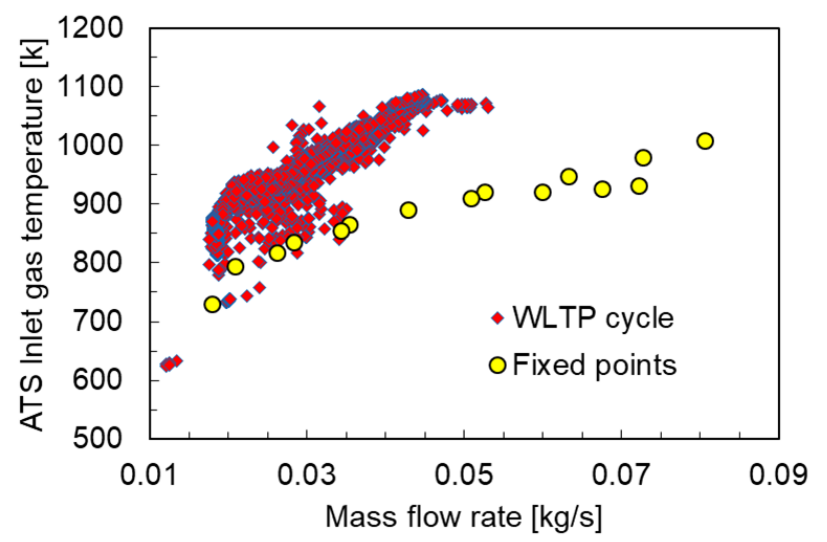

Figure 23. Cloud of points representing the gas temperature as a function of the mass flow: WLTP cycle and steady state operating points at fixed BMEP and engine speed.

It must be noted that the result is strongly dependent on the external air temperature and on the convective heat transfers around the exhaust pipes. In particular, at test bench measurements a forced convection, sometimes also intense, is always present, whereas the same forced convection cannot be realized in the underhood and underfloor region. The latter depends on the vehicle velocity which is not constant during the cycle. Therefore, during the simulation of the WLTP cycle $5 \mathrm{~m} / \mathrm{s}$ and $10 \mathrm{~m} / \mathrm{s}$ of external air velocity in the underhood and in the underfloor regions has been considered, respectively.

In terms of contribution of each single reaction path to the global activity Figure 24 shows what are the prevailing steps in the ATS. The $\mathrm{CO}$ oxidation appears to be the prevailing reaction step at most of the 
engine operating conditions. Oxidation of methane is favoured by the low mass flow rate and by the high temperature level (secondarily). The methane steam reforming reaction is more or less constant in terms of rate of conversion at all the mass flow rates and gas temperature. The hydrogen produced by this reaction plays an important role in the heat up of the catalyst since its oxidation is strongly exothermic. It must be noted that, due to the presence of oxygen in the gas stream the reduction of NO operated by the carbon monoxide is not promoted and the abatement of $\mathrm{NO}_{\mathrm{x}}$ is mainly realized via the oxygen storage reaction operated by the ceria contained in the washcoat.
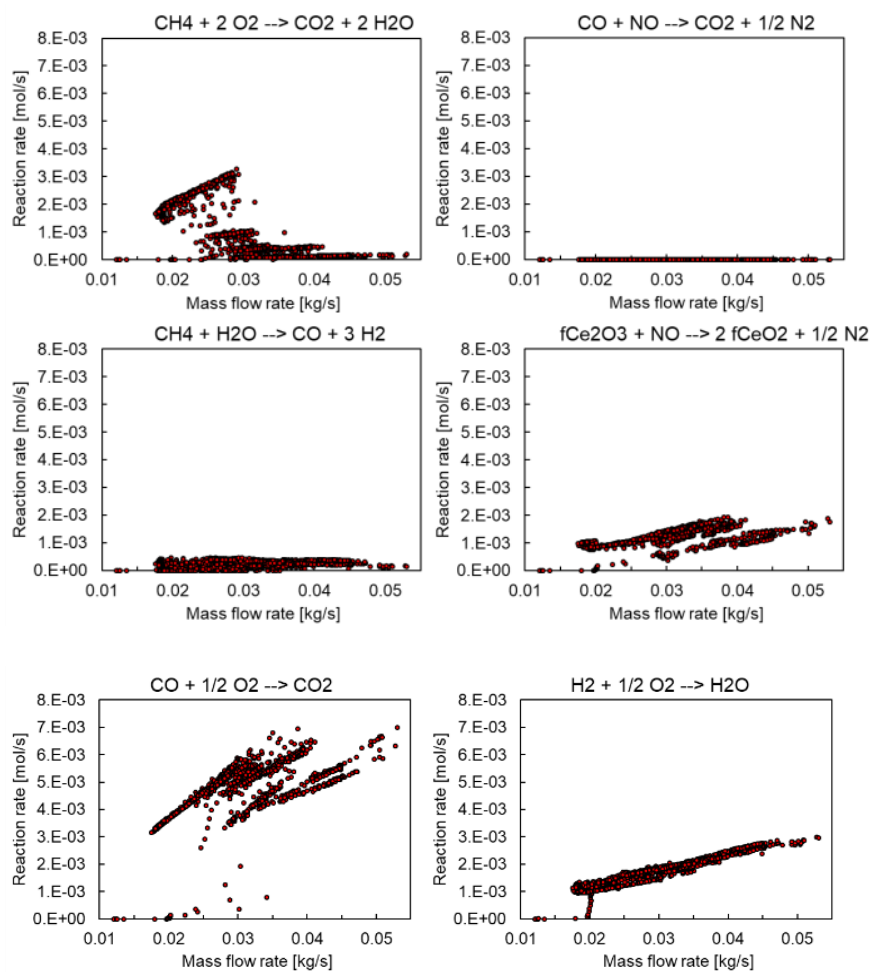

Figure 24. Different paths of the reactions taking place in the catalysts.

\section{Conclusions}

In this paper a numerical methodology to simulate the engine and aftertreatment behaviour during transient operations, such the WLTP cycle or RDE tests, has been developed and described. The proposed investigation was carried out using a 4-cylinder, spark ignition, $\mathrm{CNG}$ fuelled light duty engine; a step-by step analysis allowed to define the optimal guidelines on the required methodology to exploit available experimental data, the advantages and disadvantages of using a quasistatic approach for vehicle simulation and finally the potentialities of applying a coupled $1 D$ code-ATS model in a transient simulation in which the torque profile was derived from the quasi-static approach.

The proposed investigations outlined the expected error in the estimation of the fuel consumption (and hence $\mathrm{CO}_{2}$ per $\mathrm{km}$ ) if a quasistatic approach is used for vehicle simulation, which has the advantage of a very reduced computational time and can eventually be used in a first stage of assessment to consider different powertrain configurations.

In terms of pollutant emissions, it is required to perform the simulations in "engine transient mode" so that it can be possible to evaluate the performance of the ATS and to state whether the actual calibration and setup of the engine is sufficient to comply with the emission regulation. The model must consider the flow unsteadiness along the system and the advection of the chemical species from the engine head to the tailpipe outlet, through the catalytic converters. The results of the presented investigation have shown that, by this coupling of a 1D fluid dynamic code with a detailed ATS model, it is possible to predict the abatement of chemical species such as $\mathrm{CH}_{4}, \mathrm{NO}$ and $\mathrm{CO}$ inside catalytic converters placed in cascade configuration, under real driving vehicle operations.

\section{Acknowledgments}

This research has received funding from the European Union's Horizon 2020 programme under grant agreement No 824314, VISION_xEV project.

The authors are grateful to EMPA $(\mathrm{CH})$ for having provided the experimental data used for the validation of the numerical tool.

\section{References}

1. A. Joshi, A., Review of Vehicle Engine Efficiency and Emissions. SAE Technical Paper 2019-01-0314, 2019.

2. M. Kratzsch, W. Wukisiewitsch, M. Sens, M. Brauer, R. Tröger, The path to CO2-neutral mobility in 2050. 40th Internationales Wiener Motorensymposium, May 15-17, 2019, Wien (Austria).

3. R. Tatschl, Z. Samaras, P. Scarth, C. Beatrice, M. Mihaescu, M. Rostagno, A. Onorati, G. Moreac Njeim, C. Biet, A. Broatch, Y. Firouz, B. Deibler, D. Miljavec, M. Plieske, Virtual Component and System Integration for Efficient Electrified Vehicle Development. Proceedings of 8th Transport Research Arena TRA 2020, April 27-30, 2020, Helsinki (Finland).

4. Millo, F., Rolando, L., Andreata, M., Numerical Simulation for Vehicle Powertrain Development. 10.5772/24111, (2011).

5. Genta, G., Motor Vehicle Dynamics: Modeling and Simulation, World Scientific Pub Co Inc, 978-9-81022-911-5 Singapore, 1997.

6. A. Onorati, G. Montenegro, 1D and Multi-D Modeling Techniques for IC Engine Simulation. Chapter 11, SAE International, R-469, ISBN: 978-0-7680-9352-0, April 2020.

7. Wahiduzzaman, S., Wang, W., Leonard, A., Wenzel, S., Development of Integrated Engine/Catalyst Model for Real-Time Simulations of Control Design Options. FISITA 2010 World Automotive Congress, Budapest, Hungary, May 2010.

8. Wurzenberger, J.C., Bardubitzki, S., Bartsch, P., Katrasnik, T. Real time capable pollutant formation and exhaust aftertreatment modeling-HSDI diesel engine simulation, (2011) SAE Technical Papers.

9. Wurzenberger, J.C., Heinzle, R., Deregnaucourt, M.-V., Katrasnik, T. A comprehensive study on different system level engine simulation models (2013) SAE Technical Papers. 2013-01-1116

10.Martin, J., Arnau, F., Piqueras, P., Auñon, A. Development of an Integrated Virtual Engine Model to Simulate New Standard Testing Cycles, SAE Technical Papers 2018-01-1413, 2018-April, 
11. Montenegro, G., Onorati, A., Della Torre, A., The prediction of silencer acoustical performances by $1 \mathrm{D}, 1 \mathrm{D}-3 \mathrm{D}$ and quasi-3D nonlinear approaches. Computers and Fluids, 71, pp. 208-223, 2013.

12.Cornolti, L., Onorati, A., Cerri, T., Montenegro, G., Piscaglia, F.,1D simulation of a turbocharged Diesel engine with comparison of short and long EGR route solutions. Applied Energy, 111, pp. 1$15,2013$.

13.Stockar, S., Canova, M., Guezennec, Y., Della Torre, A., Montenegro, G., Onorati, A., Modeling wave action effects in internal combustion engine air path systems: Comparison of numerical and system dynamics approaches. International Journal of Engine Research, 14 (4), pp. 391-408, 2013.

14.D'Errico, G., Ferrari, G., Onorati, A., Cerri, T., Modeling the Pollutant Emissions from a S.I. Engine, SAE paper 2002-01-0006, 2002.

15.Corberan, J.M., Gascon, M.L., Construction of Second Order TVD Schemes for Non-Homogeneous Hyperbolic Conservation Laws. Journal of Computational Physics, vol. 172, 261-297, 2001.

16.D. E. Winterbone and R. J. Pearson. Theory of engine manifold design. Professional Engineering Publishing, London, 2000

17. Tsinoglou D. and G. Koltsakis,"Modelling of the selective catalytic NOx reduction in diesel exhaust including ammonia storage", Proceedings of the Institution of Mechanical Engineers, Part D: Journal of Automobile Engineering, 221(1): 117-133, 2007

18. Koltsakis, G.C., P.A. Konstantinidis and A.M. Stamatelos, Development and application range of mathematical models for 3way catalytic converters,Applied Catalysis B: Environmental, 12(2-3): 161-191, 1997

19. Tsinoglou, D.N., G.C. Koltsakis and J.C. Peyton Jones, Oxygen Storage Modeling in Three-Way Catalytic Converters, Industrial \& Engineering Chemistry Research, 41(5): 1152-1165, 2002.

20.Cerri, T., D'Errico, G., Montenegro, G., Onorati, A. et al., A Novel 1D Co-Simulation Framework for the Prediction of Tailpipe Emissions under Different IC Engine Operating Conditions, SAE paper 2019-24-0147, 2019.

21. Yeliana, Yeliana, Cooney, C., Worm, J., Michalek, D.J., Naber, J.D., Estimation of double-Wiebe function parameters using least square method for burn durations of ethanol-gasoline blends in spark ignition engine over variable compression ratios and EGR levels, Applied Thermal Engineering, vol. 31, issues 14-15, 2011, pages 2213-2220.

22.Merts, M., Verhelst, S., Literature Review on Dual-Fuel Combustion Modelling, SAE Paper 2019-24-0120, 2019.

23.Erickson W.D., Probhu R.K., Rapid Computation of Equilibrium Composition: and Application to Hydrocarbon Combustion. A.I.Ch.E. Journal, vol. 32 no. 7, July 1986.

24.Miller, R., Davis, G., Lavoie, G., Newman, C. and Gardner, T., A Super-Extended Zel'dovich Mechanism for NOx Modeling and Engine Calibration, SAE paper 980781, 1998.

25.Heywood J.B., Internal Combustion Engine Fundamentals. Mc Graw Hill, 1998.

26. Baruah, P.C., Combustion and Cycle Calculation in Spark Ignition Engines, in "The Thermodynamics and Gas Dynamics of Internal Combustion Engines”, Vol. II. Clarendon Press, Oxford, 1986.
27.Lavoie G., Blumberg P.N., A fundamental Model for Predicting Fuel Consumption, NOx, and HC Emissions of the Conventional Spark-Ignition Engines, Combustion Science and Technology, Vol. 21, pp 225-258, 1980.

28.Lavoie G., Adamczyk A.A., Kaiser E.W., Cooper J.W., Rothschild W.G. R, Engine HC Emissions Modeling: Partial Burn Effects, Combustion Science and Technology, Vol. 9, pp 99-105,1986.

29.Frolund, K. and Schramm, J., Simulation of HC emissions from SI engines - a parametric study, SAE paper 972893, 1997.

30.Schramm, J. and Sorenson, S.C., A Model for Hydrocarbon Emission from S.I. Engines, SAE paper 902169, 1990.

31.S. Cordiner and V. Rocco, Modeling of unburned hydrocarbon emissions in s.i. engines, Proc. ICE 97 Int. Conf., Capri (Italy), Sept. 1997.

32.J.R. Linna and S. Hochgreb, Analytical scaling model for hydrocarbon emissions from fuel absorption in oil layers in spark ignition engines, Comb. Sci. and Tech., Vol. 109, pp. 205-226, 1995.

33. Koltsakis, G.C., Kandylas, I.P., Stamatelos, A.M. Three-way catalytic converter modeling and applications (1998) Chemical Engineering Communications, 164, pp. 153-189.

34.Tsinoglou, D.N., Eggenschwiler, P.D., Thurnheer, T., Hofer, P.A simplified model for natural-gas vehicle catalysts with honeycomb and foam substrates (2009) Proceedings of the Institution of Mechanical Engineers, Part D: Journal of Automobile Engineering, 223 (6), pp. 819-834.

35.Gong, J., Wang, D., Li, J., Currier, N., Yezerets, A. Dynamic oxygen storage modeling in a three-way catalyst for natural gas engines: A dual-site and shrinking-core diffusion approach (2017) Applied Catalysis B: Environmental, 203, pp. 936-945.

36. Gühmann, C., Riese, J., von Rüden, K., Simulation and Testing for Vehicle Technology, 7th Conference, Berlin, May 12-13, 2016.

37.Dingel, O., Ross, J., Trivic, I., Cavina, N., Rioli, M., Model-Based Assessment of Hybrid Powertrain Solutions, SAE paper 2011-240070, 2011.

38.Bishop, J.D.K., Stettler, M.E.J., Molden, N., Boies, A.M., Engine maps of fuel use and emissions from transient driving cycles, Applied Energy 183 (2016) 202-217.

\section{Contact Information}

Gianluca Montenegro (gianluca.montenegro@polimi.it)

Tarcisio Cerri (tarcisio.cerri@polimi.it)

Angelo Onorati (angelo.onorati@polimi.it)

Gianluca D'Errico (gianluca.derrico@polimi.it)

Politecnico di Milano, Department of Energy,

Via Lambruschini 4, 20156 Milano - Italy

\section{Acronyms}

ATS After Treatment System

BMEP Brake Mean Effective Pressure

CFL Courant-Friedrichs-Lewy

CNG Compressed Natural Gas

EU European Union

EVO Exhaust Valve Opening 
IC Internal Combustion

NEDC New European Driving Cycle

PID Proportional-Integral-Derivative

RDE Real Drive Emission

RPM Revolution per Minute

SI Spark Ignition

TVD Total Variation Diminishing

TWC Three Way Catalyst

WLTP Worldwide Harmonised Light Vehicle Test Procedure

OD Zero-Dimensional

1D One-Dimensional 